\title{
84 Diagnosis of otosclerosis
}

A Paracusis Willisi may be present.

B Notches at $1000 \mathrm{~Hz}$ and $50 \mathrm{~Hz}$ are seen on pure tone audiometric thresholds with air conduction.

C Tympanometry is of little value.

D Vertigo is invariably due to a labyrinthine hydrops.

E Differential diagnosis from congenital footplate fixation is difficult as the conductive hearing loss is also progressive.

\section{Treatment of otosclerosis}

A Sodium fluoride therapy is employed in pure cochlear otosclerosis.

B Hearing aids halt the progression of otosclerosis.

C Surgery is not usually indicated in unilateral ears with a normal contralateral ear.

D Sensorineural losses may be encountered as late as 10 years after stapedectomy.

E Fluorides may be administered safely during pregnancy.

\section{During stapedectomy}

A Perilymph flooding may be due to an abnormally patent cochlear aqueduct.

B A floating footplate is most likely to occur in a thick type 1 footplate.

C The facial nerve presents no problems if it is in an intact fallopian canal.

D Obliterative otosclerosis should be suspected if the preoperative compliance value is less than $0.2 \mathrm{ml}$ air.

E A persistent stapedial artery is encountered in about 30 cases per 1000 stapedectomies. 